\title{
Aplicações Seqüenciais e Épocas de Aplicação de Herbicidas em Mistura com Chlorpirifos no Milho e em Plantas Daninhas ${ }^{1}$
}

\author{
Sequential Applications and Application Periods of Herbicide-Chlorpirifos Mixtures on Maize \\ and Weeds
}

\begin{abstract}
SILVA, A.A. ${ }^{2}$, FREITAS, F.M. ${ }^{3}$, FERREIRA, L.R. ${ }^{2}$, JAKELAITIS, A. ${ }^{4}$ e SILVA, A.F. ${ }^{5}$
RESUMO - Objetivou-se neste trabalho avaliar os efeitos dos herbicidas [atrazine + óleo $\left(1.200+900 \mathrm{~g} \mathrm{ha}^{-1}\right.$, respectivamente $)+$ nicosulfuron $\left.\left(28 \mathrm{~g} \mathrm{ha}^{-1}\right)\right] \mathrm{em}$ mistura no tanque do pulverizador e em aplicações seqüenciais com o inseticida chlorpirifos $\left(240 \mathrm{~g} \mathrm{ha}^{-1}\right)$ sobre as plantas daninhas e o milho, bem como os efeitos dessa mistura quando aplicada em diferentes estádios fenológicos da cultura. O híbrido de milho utilizado foi o P30F80. Em dois ensaios, os tratamentos consistiram da aplicação do chlorpirifos misturado aos herbicidas no tanque de pulverização, ou aplicado um, dois, três, quatro e cinco dias após a aplicação da mistura de herbicidas; em outro ensaio, testaram-se diferentes épocas de aplicação dos herbicidas no milho (duas, quatro e seis folhas expandidas) associados ou não ao chlorpirifos. A mistura no tanque do chlorpirifos com os herbicidas foi não-seletiva ao milho; todavia, esse inseticida não interferiu na eficiência de controle de plantas daninhas promovida pelos herbicidas nas épocas em que foi aplicado. Intervalos superiores a cinco dias entre a aplicação do chlorpirifos e da mistura de herbicidas foram necessários para evitar intoxicação do milho pelo nicosulfuron. A aplicação da mistura de herbicidas com o chlorpirifos, independentemente do estádio fenológico da cultura, reduziu a altura e a massa seca do milho.
\end{abstract}

Palavras-chave: nicosulfuron, chlorpirifos, interação.

ABSTRACT - The objective of this work was to evaluate the effects of the herbicides [atrazine + oil $\left(1.200+900 \mathrm{~g} \mathrm{ha}^{-1}\right.$, respectively) + nicosulfuron $\left.\left(28 \mathrm{~g} \mathrm{ha}^{-1}\right)\right]$ in a sprayer tank-mixture and in sequential applications of the insecticide chlorpirifos $\left(240 \mathrm{~g} \mathrm{ha}^{-1}\right)$ on weeds and maize, as well as the effect of this mixture applied at different phenological stages of the crop. The maize hybrid used was P30F80. In two experiments, the treatments consisted in the application of chlorpirifos+ herbicide sprayer tank mixtures, or chlorpirifos applied one, two, three, four, and five days after the herbicide mixture; another experiment tested different herbicide application periods (two, four, and six unfolded leaves) on maize associated or not to chlorpirifos. The chlorpirifos therbicide tank mixture was non-selective for maize. However, chlorpirifos did not interfere in the weed control efficiency of the herbicides in any of the application periods. Intervals longer than 5 days between the applications of chlorpirifos and the herbicide mixture were necessary to prevent maize intoxication by nicosulfuron. The application of the herbicides+ chlorpirifos mixture reduced height and dry mass of the maize plant, regardless of the phenological stage of the crop.

Key words: nicosulfuron, chlorpirifos, interaction.

Recebido para publicação em 29.11.2004 e na forma revisada em 5.9.2005.

Prof. do Dep. de Fitotecnia da Universidade Federal de Viçosa - UFV, 36570-000 Viçosa-MG; ${ }^{3}$ Engenheiro-Agrônomo, M.S. em Fitotecnia - UFV; ${ }^{4}$ Pós-doutorando em Fitotecnia, Dep. de Fitotecnia - UFV; ${ }^{5}$ Bolsista de Iniciação Científica do Dep. de Fitotecnia - UFV.

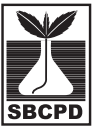

Planta Daninha, Viçosa-MG, v. 23, n. 3, p. 527-534, 2005 


\section{INTRODUÇÃO}

As plantas daninhas, quando não controladas, competem com o milho por água, luz e nutrientes, diminuindo-lhe o rendimento e a qualidade do produto colhido. Além dos prejuízos diretos, elas podem prejudicar a colheita e servir de hospedeiro para pragas e doenças (Silva \& Melhorança, 2001). Dependendo das condições edafoclimáticas, da espécie e da população de plantas daninhas, a produtividade do milho pode ser reduzida em até $85 \%$ (Blanco, 1982).

Normalmente, a época de ataque de determinadas pragas - como Spodoptera frugiperda (lagarta-do-cartucho) - no milho coincide com o momento de controle de plantas daninhas. Por isso, uma das preocupações de técnicos e produtores é conhecer as interações entre os diferentes produtos químicos (inseticidas, herbicidas) recomendados para a cultura do milho. As aplicações de inseticidas e herbicidas podem ser feitas simultânea ou seqüencialmente, havendo a possibilidade de ocorrerem interações antagônicas, aditivas ou sinérgicas (Rahman \& James, 1993). Têm-se observado interações sinérgicas entre herbicidas do grupo das sulfoniluréias e inseticidas organofosforados, com severas injúrias à cultura do milho (Diehl \& Stoller, 1990).

A seletividade das plantas às sulfoniluréias deve-se às diferentes taxas de metabolização das espécies e à velocidade de absorção e translocação desses produtos. Espécies tolerantes metabolizam rapidamente esses herbicidas, transformando-o em formas inativas por meio do sistema enzimático citocromo $\mathrm{P}_{450}$ monoxigenase, em reações de hidroxilação e glicosilação (Brow, 1990; Fonne-Pfister et al., 1990). O nicosulfuron é um herbicida sistêmico, do grupo químico das sulfoniluréias, cujo mecanismo de ação é a inibição da enzima acetolactato sintase (ALS). Ele possui boa seletividade ao milho quando aplicado sozinho, porém determinadas combinações com inseticidas organofosforados podem reduzir-lhe a seletividade à cultura (Kapusta \& Krausz, 1992).

A ocorrência de injúrias em plantas de milho após a aplicação do nicosulfuron em mistura com inseticidas tem sido atribuida à inibição da hidroxilação do nicosulfuron, ou ao aumento da absorção e translocação do herbicida nas plantas (Porpiglia et al., 1990; Moreland et al., 1993). De acordo com Lithe et al. (1992), maior toxidez tem sido observada quando o nicosulfuron é aplicado em plantas de milho oriundas de sementes tratadas com inseticidas organofosforados - como o terbufos - no sulco de plantio. Nesse caso, os sintomas no milho podem variar desde descoloração temporária das folhas até o retorcimento da planta e a paralisação do seu crescimento. Em milho, a interação entre nicosulfuron e inseticidas organofosforados reduz a taxa de metabolismo do nicosulfuron, o que causa menor tolerância da planta ao herbicida (Diehl \& Stoller, 1990). Interações semelhantes a essa têm sido observadas em outras culturas, como na soja (Campbell \& Penner, 1982; Waldrop \& Banks, 1983; Britton et al., 1982), no arroz (Khosro et al., 1986; El-Refai \& Mowafy, 1973; Bowling \& Flinchum, 1968) e no algodão (Swanson \& Swanson, 1968).

Este trabalho teve como objetivos avaliar os efeitos dos herbicidas atrazine + óleo + nicosulfuron em mistura no tanque do pulverizador e em aplicações seqüenciais com o inseticida chlorpirifos sobre plantas daninhas e a cultura do milho, assim como os efeitos dessa mistura quando aplicada em diferentes estádios fenológicos da cultura.

\section{MATERIAL E MÉTODOS}

Três experimentos foram conduzidos em vasos em casa de vegetação, utilizando como substrato Argissolo Vermelho-Amarelo com pH em água de 5,8; H+Al, Ca e Mg de 4,3, 3,8 e $1,4 \mathrm{cmol}_{\mathrm{c}} \mathrm{dm}^{-3}$, respectivamente; $\mathrm{P}$ de $1,4 \mathrm{mg} \mathrm{dm}^{-3}$; K de $123 \mathrm{mg} \mathrm{dm}^{-3}$, matéria orgânica de 2,18 dag $\mathrm{kg}^{-1}$; e textura argilo-arenosa.

No primeiro experimento, avaliaram-se os efeitos da mistura dos herbicidas nicosulfuron + atrazine + óleo associados ao inseticida chlorpirifos sobre o milho. Os tratamentos constaram da aplicação simultânea do chlorpirifos (240 $\mathrm{g} \mathrm{ha}^{-1}$ ) com a mistura de herbicidas atrazine + óleo $\left(1.200+900 \mathrm{~g} \mathrm{ha}^{-1}\right.$, respectivamente) + nicosulfuron $\left(28 \mathrm{~g} \mathrm{ha}^{-1}\right)$ e da aplicação do inseticida um, dois, três, quatro e cinco dias depois dos herbicidas. Incluiu-se também uma testemunha sem herbicida. O delineamento utilizado foi o de 
blocos casualizados, com quatro repetições. Cada unidade experimental foi constituída de um vaso, com $6 \mathrm{~L}$ de solo adubado com $24 \mathrm{~g}$ da formulação 4:14:8 (N: $\left.\mathrm{P}_{2} \mathrm{O}_{5}: \mathrm{K}_{2} \mathrm{O}\right)$.

O híbrido de milho P30F80 foi semeado em setembro de 2002, empregando-se cinco sementes por vaso. Dez dias após a emergência, fez-se o desbaste para duas plantas por vaso. O teor de água do substrato nos vasos foi mantido próximo à capacidade de campo, por meio de duas irrigações diárias.

As aplicações foram feitas com pulverizador costal pressurizado com $\mathrm{CO}_{2}$, com

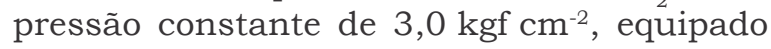
com dois bicos da série XR 110.02, espaçados de $0,5 \mathrm{~m}$, e calibrados para aplicar o equivalente a $200 \mathrm{~L} \mathrm{ha}^{-1}$ de calda. A primeira aplicação foi feita aos 20 dias após a emergência (DAE) do milho.

Avaliaram-se, no milho, a toxicidade, a altura das plantas e o diâmetro do colmo aos 7, 14 e 28 dias após aplicação (DAA) dos produtos. A toxicidade foi avaliada atribuindo-se notas de zero a $100 \%$, em que zero indica ausência de sintoma de toxicidade e 100, morte das plantas de milho. A altura foi medida a partir da base da planta (rente ao substrato) até a última folha completamente expandida, e o diâmetro do colmo foi medido a $5 \mathrm{~cm}$ de altura, com um paquímetro. Aos 60 DAE, as plantas de milho foram cortadas rente ao solo, secadas em estufa de ventilação forçada a $70{ }^{\circ} \mathrm{C}$ por 72 horas e pesadas, para determinação da massa seca.

No segundo experimento - conduzido simultaneamente ao primeiro - avaliou-se o controle de plantas daninhas pelas misturas dos produtos descritos no experimento anterior. Nesse caso, em cada parcela, foram semeadas, juntamente com o milho, as espécies daninhas Bidens pilosa (picão-preto), Digitaria horizontalis (capim-colchão), Ipomoea grandifolia (corda-de-viola), Brachiaria plantaginea (capim-marmelada) e Brachiaria decumbens (capim-braquiária) nas densidades de 20,20, 4, 10 e 5 plantas vaso-1, respectivamente. Aos 7, 14 e 28 DAA foi feita a avaliação visual da porcentagem de controle das plantas daninhas, e aos 60 DAE, a determinação da massa seca das plantas daninhas e do milho.
No terceiro experimento, avaliaram-se os efeitos da mistura dos herbicidas [atrazine + óleo $\left(1.200+900 \mathrm{~g} \mathrm{ha}^{-1}\right.$, respectivamente $\left.)\right]+$ nicosulfuron (28 $\mathrm{g} \mathrm{ha}^{-1}$ ) associados ou não ao chlorpirifos (240 $\mathrm{g} \mathrm{ha}^{-1}$ ), e aplicados em diferentes estádios de desenvolvimento do milho. O experimento foi delineado em blocos ao acaso, em esquema fatorial $3 \times 2+1$, com quatro repetições, em que o primeiro fator foram as épocas de aplicação dos produtos (milho com duas, quatro ou seis folhas expandidas); o segundo fator, a ausência ou presença do chlorpirifos; e a testemunha, constituída pela ausência desses produtos. Da mesma forma, foram avaliados a altura, o diâmetro e a toxicidade, aos 7, 14 e 28 DAA, e a massa seca do milho, aos 60 DAE.

Os dados do primeiro e do segundo experimento foram submetidos à análise de variância e, no caso de o teste $\mathrm{F}$ ter sido significativo, procedeu-se à comparação de médias pelo teste de Tukey a $5 \%$ de probabilidade. Para efeito de análise, os dados de massa seca de plantas daninhas foram transformados em $\sqrt{\mathrm{x}+1}$. No terceiro experimento, além do teste de Tukey, utilizou-se o teste de Dunnet para comparação das médias dos tratamentos com a testemunha.

\section{RESULTADOS E DISCUSSÃO}

No primeiro experimento, aos 7 DAA, não se observaram diferenças significativas em relação à altura das plantas de milho (Tabela 1). Entretanto, aos 14 e 28 DAA ficaram evidentes os efeitos negativos dos herbicidas aplicados em mistura no tanque do pulverizador com chlorpirifos sobre essa variável. Aos 14 DAA, observou-se, nos tratamentos em que o chlorpirifos foi aplicado simultaneamente aos herbicidas e quando a aplicação do chlorpirifos foi realizada um dia após, que o crescimento do milho foi inferior ao da testemunha (Tabela 1). No entanto, não se observou diferença quando a aplicação do chlorpirifos foi feita dois, três, quatro e cinco dias após aplicação dos herbicidas. Aos 28 DAA, somente onde se realizou a mistura no tanque do chlorpirifos com os herbicidas a altura das plantas foi inferior à dos demais tratamentos. De acordo com Porpiglia et al. (1990) e Moreland et al. (1993), a redução do crescimento das plantas, quando a mistura do 
herbicida é feita com o chlorpirifos, pode ser atribuída à inibição do metabolismo do nicosulfuron, ou ao aumento da absorção e translocação do herbicida nas plantas. Comportamento semelhante ao da altura de plantas foi observado com o diâmetro do colmo (Tabela 1).

Aos 7 DAA, todos os produtos causaram toxidez ao milho (Tabela 1). Contudo, no tratamento em que se aplicou a mistura dos herbicidas mais o chlorpirifos a toxidez às plantas de milho foi maior. Aos 14 DAA, os sintomas de toxidez do nicosulfuron nas plantas de milho foram pequenas manchas estriadas de clorose acompanhando as nervuras das folhas e por enrugamento nas suas bordas. Nos tratamentos com chlorpirifos misturado no tanque com os herbicidas, além da clorose, verificou-se morte da gema apical e perfilhamento das plantas. Quando o chlorpirifos foi aplicado um dia após os herbicidas, os sintomas de toxidez também foram maiores, em relação aos tratamentos em que o inseticida foi aplicado dois, três, quatro e cinco dias após os herbicidas (Tabela 1). Aos 28 DAA, verificou-se recuperação das plantas em todos os tratamentos, com exceção daquele pulverizado com a mistura no tanque dos herbicidas mais o chlorpirifos (toxicidade de $82 \%$ ) e quando o chlorpirifos foi aplicado um dia após os herbicidas $(56,25 \%)$. O fato de essas interações entre os herbicidas e o chlorpirifos ocorrerem quando os produtos são aplicados em intervalos um do outro de até 24 horas pode indicar que o inseticida interferiu no metabolismo do nicosulfuron, ou também que essa interação pode ter sido provocada por mudança química da mistura pulverizada, dada pela ativação do nicosulfuron pelo chlorpirifos, ou vice-versa (Campbell \& Penner, 1982).

No segundo experimento, observou-se que a eficiência dos herbicidas no controle de Bidens pilosa, Digitaria horizontalis, Ipomoea grandifolia, Brachiaria plantaginea e Brachiaria decumbens não foi influenciada pelo chlorpirifos em mistura com os herbicidas. De forma geral, aos 28 DAA, verificou-se que a eficiência de controle das espécies daninhas $B$. pilosa, I. grandifolia, B. plantaginea e $B$. decumbens proporcionada por todas as misturas foi superior a $90 \%$. Todavia, para $D$. horizontalis, verificou-se que a porcentagem de controle foi inferior a 90\%, evidenciando a eficiência regular desses herbicidas no controle desta espécie daninha. Esses resultados são confirmados na Tabela 2 , onde se observa que a massa seca das espécies daninhas não diferiu entre os tratamentos que receberam herbicidas, independentemente da mistura com chlorpirifos. Constatou-se também que a massa seca de todas as espécies daninhas, em todos os tratamentos com herbicidas, foi inferior à da testemunha não-tratada, à exceção de $D$. horizontalis, evidenciando a tolerância dessa espécie aos herbicidas avaliados (Tabela 2).

Tabela 1 - Altura, diâmetro de colmo e toxicidade em plantas de milho avaliadas aos 7, 14 e 28 dias após a aplicação (DAA) dos tratamentos. Viçosa-MG

\begin{tabular}{|c|c|c|c|c|c|c|c|c|c|}
\hline \multirow{2}{*}{ Tratamento } & \multicolumn{3}{|c|}{ Altura $(\mathrm{cm})$} & \multicolumn{3}{|c|}{ Diâmetro (mm) } & \multicolumn{3}{|c|}{ Toxicidade (\%) } \\
\hline & 7 DAA & $14 \mathrm{DAA}$ & $28 \mathrm{DAA}$ & $7 \mathrm{DAA}$ & $14 \mathrm{DAA}$ & $28 \mathrm{DAA}$ & $7 \mathrm{DAA}$ & 14 DAA & $28 \mathrm{DAA}$ \\
\hline Testemunha & $28,13 \mathrm{a}$ & $42,75 \mathrm{a}$ & $67,13 \mathrm{a}$ & $6,39 \mathrm{a}$ & $10,53 \mathrm{a}$ & $12,77 \mathrm{a}$ & $0,00 \mathrm{~d}$ & $0,0 \mathrm{c}$ & $0,00 \mathrm{c}$ \\
\hline$(\text { Atrazine }+ \text { óleo })^{1 /}+$ nicosulfuron ${ }^{2 /}$ & $26,81 \mathrm{a}$ & $42,94 \mathrm{a}$ & $71,00 \mathrm{a}$ & $6,23 \mathrm{a}$ & $11,60 \mathrm{a}$ & $13,00 \mathrm{a}$ & $24,50 \mathrm{c}$ & $11,00 \mathrm{bc}$ & $0,00 \mathrm{c}$ \\
\hline (Atrazine + óleo) + nicosulfuron + chlorpirifos ${ }^{3 /} \mathrm{em}_{\text {mistura no tanque }}$ & $24,25 \mathrm{a}$ & $25,38 \mathrm{c}$ & $31,13 \mathrm{~b}$ & $5,85 \mathrm{a}$ & $7,55 \mathrm{~b}$ & $8,21 \mathrm{~b}$ & $46,25 \mathrm{a}$ & $72,50 \mathrm{a}$ & $82,00 \mathrm{a}$ \\
\hline (Atrazine + óleo) + nicosulfuron + chlorpirifos, $1 \mathrm{DAA}^{4}$ & $25,88 \mathrm{a}$ & $31,69 \mathrm{bc}$ & $66,75 \mathrm{a}$ & $6,24 \mathrm{a}$ & $10,49 a b$ & $12,79 \mathrm{a}$ & $28,00 \mathrm{bc}$ & $65,00 \mathrm{a}$ & $56,25 \mathrm{~b}$ \\
\hline (Atrazine + óleo) + nicosulfuron + chlorpirifos, 2 DAA & $24,63 \mathrm{a}$ & $41,50 \mathrm{ab}$ & $75,75 \mathrm{a}$ & $6,20 \mathrm{a}$ & $10,76 \mathrm{a}$ & $13,34 \mathrm{a}$ & $36,00 \mathrm{ab}$ & $15,50 \mathrm{bc}$ & $7,50 \mathrm{c}$ \\
\hline (Atrazine + óleo) + nicosulfuron + chlorpirifos, 3 DAA & $25,63 \mathrm{a}$ & $38,82 \mathrm{ab}$ & $76,75 \mathrm{a}$ & $6,49 \mathrm{a}$ & $11,98 \mathrm{a}$ & $13,29 \mathrm{a}$ & $33,00 \mathrm{bc}$ & $25,00 \mathrm{~b}$ & $2,50 \mathrm{c}$ \\
\hline (Atrazine + óleo) + nicosulfuron + chlorpirifos, 4 DAA & $24,06 \mathrm{a}$ & $39,50 \mathrm{ab}$ & $76,50 \mathrm{a}$ & $6,60 \mathrm{a}$ & $12,33 \mathrm{a}$ & $14,31 \mathrm{a}$ & $\begin{array}{ll}33,75 \mathrm{bc} \\
33,7 \mathrm{cos}\end{array}$ & $23,75 \mathrm{bc}$ & $\begin{array}{ll}6,25 \mathrm{c} \\
\ldots, 2 \ldots\end{array}$ \\
\hline$($ Atrazine + óleo ) + nicosulfuron + chlorpirifos, 5 DAA & $25,88 \mathrm{a}$ & $41,88 \mathrm{a}$ & $80,50 \mathrm{a}$ & $6,58 \mathrm{a}$ & $10,97 \mathrm{a}$ & $13,13 \mathrm{a}$ & $33,75 \mathrm{bc}$ & $18,00 \mathrm{bc}$ & $0,0 \mathrm{c}$ \\
\hline CV (\%) & 9,41 & 11,07 & 12,83 & 10,15 & 11,52 & 12,83 & 16,07 & 26,25 & 41,42 \\
\hline
\end{tabular}

1/ Mistura pronta denominada Primóleo com atrazine + óleo $\left(400+300 \mathrm{~g} \mathrm{~L}^{-1}\right)$; $\stackrel{2}{ }$ Produto comercial denominado Sanson, formulado como suspensão concentrada (SC) com $40 \mathrm{~g} \mathrm{~L}^{-1}$ de nicosulfuron; ${ }^{3 /}$ Produto comercial denominado Lorsban, formulado como concentrado emulsionável (CE) com $480 \mathrm{~g} \mathrm{~L}^{-1}$ de chlorpirifos; $\mathrm{e}^{4 /} \mathrm{DAA}=$ dias após aplicação dos herbicidas (atrazine+óleo) + nicosulfuron.

As médias seguidas da mesma letra, nas colunas, não diferem entre si a 5\% de probabilidade pelo teste de Tukey. 
Tabela 2 - Massa seca de Bidens pilosa (BIDPI), Digitaria horizontalis (DIGHO), Brachiaria plantaginea (BRAPL), Brachiaria decumbens (BRADE) e Ipomoea grandifolia (IPOGR) aos 60 dias após a emergência do milho. Viçosa-MG

\begin{tabular}{|c|c|c|c|c|c|}
\hline \multirow{2}{*}{ Tratamento } & \multicolumn{5}{|c|}{ Massa seca (g por vaso) } \\
\hline & BIDPI & DIGHO & BRAPL & BRADE & IPOGR \\
\hline Testemunha & $4,14 \mathrm{a}$ & $1,32 \mathrm{a}$ & $1,85 \mathrm{a}$ & $4,03 \mathrm{a}$ & 2,03 a \\
\hline$(\text { Atrazine }+ \text { óleo })^{1 /}+$ nicosulfuron $^{2 /}$ & $1,28 \mathrm{~b}$ & $1,02 \mathrm{a}$ & $1,42 \mathrm{~b}$ & $2,00 \mathrm{~b}$ & $1,02 \mathrm{~b}$ \\
\hline (Atrazine + óleo) + nicosulfuron + chlorpirifos ${ }^{3 /}$ em mistura no tanque & $1,12 \mathrm{~b}$ & $1,04 \mathrm{a}$ & $1,42 \mathrm{~b}$ & $2,00 \mathrm{~b}$ & $1,03 \mathrm{~b}$ \\
\hline (Atrazine + óleo) + nicosulfuron + chlorpirifos, $1 \mathrm{DAA}^{4 /}$ & $1,23 \mathrm{~b}$ & $1,08 \mathrm{a}$ & $1,41 \mathrm{~b}$ & $2,00 \mathrm{~b}$ & $1,06 \mathrm{~b}$ \\
\hline (Atrazine + óleo) + nicosulfuron + chlorpirifos, 2 DAA & $1,24 \mathrm{~b}$ & $1,04 \mathrm{a}$ & $1,43 \mathrm{~b}$ & $2,00 \mathrm{~b}$ & $1,03 \mathrm{~b}$ \\
\hline (Atrazine + óleo) + nicosulfuron + chlorpirifos, 3 DAA & $1,30 \mathrm{~b}$ & $1,09 \mathrm{a}$ & $1,42 \mathrm{~b}$ & $2,02 \mathrm{~b}$ & $1,03 \mathrm{~b}$ \\
\hline (Atrazine + óleo) + nicosulfuron + chlorpirifos, 4 DAA & $1,64 \mathrm{~b}$ & $1,09 \mathrm{a}$ & $1,42 \mathrm{~b}$ & $2,06 \mathrm{~b}$ & $1,02 \mathrm{~b}$ \\
\hline (Atrazine + óleo) + nicosulfuron + chlorpirifos, 5 DAA & $1,61 \mathrm{~b}$ & $1,15 \mathrm{a}$ & $1,43 \mathrm{~b}$ & $2,02 \mathrm{~b}$ & $1,06 \mathrm{~b}$ \\
\hline CV $(\%)$ & 23,90 & 12,83 & 2,65 & 18,46 & 23,85 \\
\hline
\end{tabular}

1/ Mistura pronta denominada Primóleo com atrazine + óleo $\left(400+300 \mathrm{~g} \mathrm{~L}^{-1}\right)$; ${ }^{2}$ Produto comercial denominado Sanson, formulado como suspensão concentrada (SC) com $40 \mathrm{~g} \mathrm{~L}^{-1}$ de nicosulfuron; ${ }^{3 /}$ Produto comercial denominado Lorsban, formulado como concentrado emulsionável (CE) com $480 \mathrm{~g} \mathrm{~L}^{-1}$ de chlorpirifos; $\mathrm{e}^{4 /} \mathrm{DAA}=$ dias após aplicação dos herbicidas (atrazine+óleo) + nicosulfuron.

As médias seguidas da mesma letra, nas colunas, não diferem entre si a $5 \%$ de probabilidade pelo teste de Tukey. Dados transformados por $\sqrt{X+1}$.

A perda da seletividade do nicosulfuron ao milho, quando em mistura com o chlorpirifos - observada no primeiro experimento -, foi confirmada pela menor massa seca produzida pelas plantas de milho (Tabela 3). Nessa condição, a mistura dos herbicidas com o chlorpirifos reduziu o acúmulo de massa seca de milho, em relação à testemunha nãotratada, em aproximadamente $80 \%$. Já no segundo experimento a redução da massa seca do milho provocada pela mistura no tanque dos herbicidas com o chlorpirifos foi semelhante àquela causada pela interferência das plantas daninhas (Tabela 3). Também se observou que a massa seca do tratamento em que foram aplicados apenas os herbicidas não diferiu daquelas em que o chlorpirifos foi aplicado um, dois, três, quatro e cinco dias após a aplicação dos herbicidas, os quais não diferiram da testemunha (Tabela 3).

No terceiro experimento, observou-se interação significativa entre a mistura do chlorpirifos aos herbicidas e a época de aplicação destes sobre a altura, o diâmetro e a toxicidade às plantas de milho (Tabela 4). A aplicação da mistura dos herbicidas com o chlorpirifos no estádio de duas, quatro e seis folhas diminuiu o crescimento das plantas, em relação à testemunha, em avaliações feitas aos 7, 14 e 28 DAA (Tabela 4). Segundo Kwon et al. (1995), os herbicidas inibidores da acetolactato sintase, como o nicosulfuron, são metabolizados por diferentes isoenzimas do complexo $\mathrm{P}_{450}$ monoxigenase, havendo especificidade não somente para grupos químicos, mas também entre herbicidas dentro de um mesmo grupo químico. Nesse sentido, provavelmente, a isoenzima responsável pela metabolização do nicosulfuron tenha sido inibida pelo chlorpirifos, o que pode ter contribuído para a toxicidade do herbicida às plantas, reduzindo o seu crescimento. Aos 7 DAA, no tratamento que recebeu apenas os herbicidas, a altura das plantas de milho foi inferior à da testemunha. Todavia, aos 14 e 28 DAA essa diferença não foi observada, demonstrando a recuperação do milho quando não se mistura chlorpirifos aos herbicidas (Tabela 4).

Quanto aos efeitos dos tratamentos sobre o diâmetro do colmo em aplicações realizadas no estádio de duas folhas, observou-se que, aos 7 DAA, não ocorreu diferença entre os tratamentos com e sem chlorpirifos; no entanto, essa diferença tornou-se evidente a partir dos 14 DAA, em que a mistura dos herbicidas com chlorpirifos reduziu o diâmetro, em relação à testemunha não-tratada (Tabela 4). Aos 14 e 28 DAA, não se verificou diferença entre o tratamento somente com herbicidas e a testemunha não-tratada (Tabela 4).

Quando os herbicidas foram misturados no tanque com chlorpirifos e aplicados no estádio de quatro folhas, o diâmetro do colmo foi menor em relação ao da testemunha não-tratada, em 
avaliações feitas aos 14 e 28 DAA, respectivamente. Entretanto, as diferenças entre os tratamentos com e sem chlorpirifos foram menores no tocante à aplicação no estádio de duas folhas. Esses resultados estão de acordo com as observações de Costa \& Marchezan (1982), os quais sugerem que, pelo fato de o colmo já estar formado no momento da aplicação dos tratamentos, a diferença entre eles será menor. O mesmo pode ser observado quando a aplicação dos tratamentos foi feita no estádio de seis folhas, na qual não foram encontradas alterações significativas entre os tratamentos com e sem chlorpirifos. Aos 28 DAA, o fato de a testemunha apresentar diâmetro inferior aos tratamentos com chlorpirifos em aplicações realizadas no estádio de seis folhas pode ser atribuido ao engrossamento do caule - sintoma de toxidez provocado pela mistura do nicosulfuron + chlorpirifos.

Observou-se que aos 7 DAA, quando as aplicações foram feitas no estádio de duas folhas, não se verificou diferença de toxidez nas plantas de milho entre os tratamentos sem e com chlorpirifos (Tabela 4). Entretanto, aos 14 e 28 DAA, essa diferença tornou-se evidente, observando-se recuperação das plantas de milho quando não se misturou o chlorpirifos aos herbicidas. Quando o chlorpirifos foi adicionado aos herbicidas, constatou-se, aos 28 DAA, severa toxicidade à cultura $(92,5 \%)$.

Tabela 3 - Massa seca das plantas de milho aos 60 dias após a emergência (DAE). Viçosa-MG

\begin{tabular}{|c|c|c|}
\hline \multirow{2}{*}{ Tratamento } & \multicolumn{2}{|c|}{ Biomassa seca (g por vaso) } \\
\hline & $1^{\circ}$ experimento & $2^{-0}$ experimento \\
\hline Testemunha $^{1 /}$ & $43,79 \mathrm{a}$ & $15,48 \mathrm{bc}$ \\
\hline (Atrazine + óleo $)^{/ / 4}+$ nicosulfuron ${ }^{3}$ & $34,66 \mathrm{a}$ & $39,62 \mathrm{a}$ \\
\hline (Atrazine + óleo) + nicosulfuron + chlorpirifos ${ }^{4}$ em mistura no tanque & $9,07 \mathrm{~b}$ & $5,17 \mathrm{c}$ \\
\hline (Atrazine + óleo) + nicosulfuron + chlorpirifos, $1 \mathrm{DAA}^{\mathrm{s}^{-}}$ & $29,69 \mathrm{a}$ & $28,07 \mathrm{ab}$ \\
\hline (Atrazine + óleo $)+$ nicosulfuron + chlorpirifos, 2 DAA & $36,01 \mathrm{a}$ & $30,91 \mathrm{ab}$ \\
\hline (Atrazine + óleo) + nicosulfuron + chlorpirifos, 3 DAA & $34,23 \mathrm{a}$ & $32,37 \mathrm{ab}$ \\
\hline (Atrazine + óleo) + nicosulfuron + chlorpirifos, 4 DAA & $40,65 \mathrm{a}$ & $33,86 a b$ \\
\hline (Atrazine + óleo) + nicosulfuron + chlorpirifos, 5 DAA & $38,35 \mathrm{a}$ & $34,25 \mathrm{ab}$ \\
\hline CV $(\%)$ & 24,87 & 32,52 \\
\hline
\end{tabular}

$1 /$ No primeiro experimento a testemunha correspondeu somente ao milho, e no segundo, ao milho na presença de plantas daninhas; ${ }^{2} /$ Mistura pronta denominada Primóleo com atrazine + óleo $\left(400+300 \mathrm{~g} \mathrm{~L}^{-1}\right)$; $\stackrel{3}{3}$ Produto comercial denominado Sanson, formulado como suspensão concentrada (SC) com $40 \mathrm{~g} \mathrm{~L}^{-1}$ de nicosulfuron; ${ }^{4 /}$ Produto comercial denominado Lorsban, formulado como concentrado emulsionável (CE) com $480 \mathrm{~g} \mathrm{~L}^{-1}$ de chlorpirifos; $\mathrm{e}^{\frac{5}{2}} \mathrm{DAA}=$ dias após aplicação dos herbicidas (atrazine+óleo) + nicosulfuron.

As médias seguidas da mesma letra, nas colunas, não diferem entre si a 5\% de probabilidade pelo teste de Tukey.

Tabela 4 - Altura, diâmetro de colmo e toxicidade em plantas de milho avaliadas aos 7, 14 e 28 dias após a aplicação (DAA) dos tratamentos nos estádios de duas, quatro e seis folhas expandidas, na ausência e na presença do chlorpirifos. Viçosa-MG

\begin{tabular}{|c|c|c|c|c|c|c|c|c|c|}
\hline \multirow{2}{*}{ Tratamento } & \multicolumn{3}{|c|}{ Altura de plantas $(\mathrm{cm})$} & \multicolumn{3}{|c|}{ Diâmetro de colmo (mm) } & \multicolumn{3}{|c|}{ Toxicidade (\%) } \\
\hline & $7 \mathrm{DAA}$ & $14 \mathrm{DAA}$ & $28 \mathrm{DAA}$ & $7 \mathrm{DAA}$ & $14 \mathrm{DAA}$ & $28 \mathrm{DAA}$ & $7 \mathrm{DAA}$ & $14 \mathrm{DAA}$ & $28 \mathrm{DAA}$ \\
\hline \multicolumn{10}{|c|}{ Duas folhas } \\
\hline Sem chlorpirifos & $13,50(-) \mathrm{Ac}$ & $26,00 \mathrm{Ac}$ & $44,69 \mathrm{Ab}$ & $5,98 \mathrm{Ac}$ & $11,60 \mathrm{Ab}$ & $14,28 \mathrm{Ab}$ & $57,50(+) \mathrm{Aa}$ & $35,00(+) \mathrm{Ba}$ & $17,50(+) \mathrm{Ba}$ \\
\hline Com chlorpirifos & $11,94(-) \mathrm{Ac}$ & $12,63(-) \mathrm{Bc}$ & $13,30(-) \mathrm{Bb}$ & $4,94 \mathrm{Ac}$ & $5,18(-) \mathrm{Bc}$ & $5,9(-) \mathrm{Bc}$ & $58,75(+) \mathrm{Aa}$ & $83,75(+) \mathrm{Aa}$ & $92,50(+) \mathrm{Aa}$ \\
\hline Testemunha & 18,80 & 29,81 & 48,31 & 5,55 & 12,20 & 15,47 & 0 & 0 & 0 \\
\hline \multicolumn{10}{|c|}{ Quatro folhas } \\
\hline Sem chlorpirifos & $23,88(-) \mathrm{Ab}$ & $45,88 \mathrm{Ab}$ & $65,19 \mathrm{Aa}$ & $12,43 \mathrm{Ab}$ & $15,81 \mathrm{Aa}$ & $14,84 \mathrm{Ab}$ & $42,5(+) \mathrm{Ba}$ & $7,50 \mathrm{Bb}$ & $2,50 \mathrm{Bb}$ \\
\hline Com chlorpirifos & $20,19(-) \mathrm{Bb}$ & $20,50(-) \mathrm{Bb}$ & $20,06(-) \mathrm{Bb}$ & $9,85(-) \mathrm{Bb}$ & $10,38(-) \mathrm{Bb}$ & $9,80(-) \mathrm{Bb}$ & $57,5(+) \mathrm{Aa}$ & $78,75(+) \mathrm{Aa}$ & $82,50(+) \mathrm{Aa}$ \\
\hline Testemunha & 29,81 & 48,31 & 65,81 & 12,20 & 15,47 & 15,14 & 0 & 0 & 0 \\
\hline \multicolumn{10}{|c|}{ Seis folhas } \\
\hline Sem chlorpirifos & $40,63(-) \mathrm{Aa}$ & $66,50 \mathrm{Aa}$ & $68,81 \mathrm{Aa}$ & $17,01(+) \mathrm{Aa}$ & 16,46(+)Aa & $16,93 \mathrm{Aa}$ & $26,25(+) \mathrm{Bb}$ & $28,75(+) \mathrm{Ba}$ & $24,50(+) \mathrm{Ba}$ \\
\hline Com chlorpirifos & $33,81(-) \mathrm{Ba}$ & $33,44(-) \mathrm{Ba}$ & $33,81(-) \mathrm{Ba}$ & $15,63 \mathrm{Ba}$ & $16,45(+) \mathrm{Aa}$ & $17,40(+) \mathrm{Aa}$ & $43,75(+) \mathrm{Aa}$ & $62,50(+) \mathrm{Ab}$ & $70,00(+) \mathrm{Ab}$ \\
\hline Testemunha & 48,31 & 65,81 & 72,86 & 15,47 & 15,14 & $15,00 \mathrm{Ba}$ & 0 & 0 & 0 \\
\hline
\end{tabular}

Nas colunas, as letras maiúsculas comparam as médias do chlorpirifos em cada estádio de aplicação, e as minúsculas, nas linhas, comparam as médias dos estádios de aplicação na ausência e na presença de chlorpirifos, pelo teste de Tukey a 5\% de probabilidade. As médias seguidas de (-) foram inferiores às da testemunha pelo teste de Dunnet a $5 \%$ de probabilidade. 
No estádio de quatro folhas, os sintomas de toxidez observados aos 7, 14 e 28 DAA foram diferentes entre os tratamentos que receberam apenas os herbicidas e os que receberam o chlorpirifos (Tabela 4). Os sintomas nos tratamentos sem chlorpirifos variaram de moderado (7 DAA) a nulo (14 e 28 DAA), e naqueles que receberam o chlorpirifos, de moderado (7 DAA) a muito forte (14 e 28 DAA). No estádio de seis folhas, os sintomas de toxidez no tratamento sem chlorpirifos foi leve aos 7,14 e 28 DAA e variou de moderado (7 e 14 DAA) a forte (28 DAA) nos tratamentos com chlorpirifos (Tabela 4). Isso mostra que, independentemente do estádio de aplicação do nicosulfuron, se a este for adicionado o chlorpirifos, poderá ocorrer intoxicação da cultura, prejudicando as plantas de milho.

Quanto à massa seca do milho avaliado aos $60 \mathrm{DAE}$, verificou-se que quando os herbicidas foram misturados no tanque com chlorpirifos, em aplicações realizadas no estádio de duas folhas, a massa seca foi menor em relação à da testemunha não-tratada, em aproximadamente $95 \%$, enquanto a aplicação isolada dos herbicidas foi de $28 \%$. Nessa condição, observou-se também menor massa seca do milho nos estádios de quatro a seis folhas, com redução de 80 e 46\%, respectivamente (Tabela 5). A aplicação isolada dos herbicidas nos estádios de quatro a seis folhas proporcionou menor massa seca das plantas de milho, em relação à testemunha não-tratada, em aproximadamente 14\%, sendo, portanto, inferior à interferência negativa causada quando a aplicação foi realizada no estádio de duas folhas (28\%).

Tabela 5 - Massa seca das plantas de milho (g por vaso) avaliadas aos 60 dias após a emergência, referentes aos estádios de duas, quatro e seis folhas expandidas, na ausência e na presença do chlorpirifos. Viçosa-MG

\begin{tabular}{|l|c|c|c|}
\hline \multirow{2}{*}{ Tratamento } & \multicolumn{3}{|c|}{ Estádio de aplicação } \\
\cline { 2 - 4 } & Duas folhas & Quatro folhas & Seis folhas \\
\hline Sem chlorpirifos & $27,83(-) \mathrm{Ab}$ & $33,46(-) \mathrm{Aa}$ & $33,78(-) \mathrm{Aa}$ \\
\hline Com chlorpirifos & $1,91(-) \mathrm{Bc}$ & $7,59(-) \mathrm{Bb}$ & $20,88(-) \mathrm{Ba}$ \\
\hline Testemunha & 38,73 & 38,73 & 38,73 \\
\hline
\end{tabular}

Nas colunas, as letras maiúsculas comparam as médias do chlorpirifos em cada estádio de aplicação, e as minúsculas, nas linhas, comparam as médias dos estádios de aplicação na ausência e na presença de chlorpirifos, pelo teste de Tukey a $5 \%$ de probabilidade. As médias seguidas de (-) foram inferiores às da testemunha pelo teste de Dunnet a $5 \%$ de probabilidade.
Em conclusão, o chlorpirifos não interfere na eficiência de controle de plantas daninhas promovida pelos herbicidas, independentemente da época de aplicação dos produtos. Por sua vez, em mistura no tanque com os herbicidas, a mistura formada foi não-seletiva ao milho híbrido P30F80; já em aplicações seqüenciais são necessários intervalos superiores a cinco dias entre a aplicação do chlorpirifos e da mistura de herbicidas para minimizar a intoxicação do milho pelo nicosulfuron. A aplicação da mistura de herbicidas com o chlorpirifos - independentemente do estádio fenológico da cultura afeta as plantas de milho.

\section{LITERATURA CITADA}

BLANCO, H. G. Ecologia das plantas daninhas.

Competição de plantas daninhas em culturas brasileiras. In: Controle de plantas daninhas. Campinas: Instituto Biológico, 1982. p. 43-75.

BOWLING, C. C.; FLINCHUM, W. T. Interaction of propanil with insecticides applied as seed treatments on rice. J. Econ. Entomol., v. 16, p. 67-69, 1968.

BRITTON, D. W. et al. Infuence of preemergence temperature on the interaction of metribuzin with organophosphate insecticide-nematicides in soybeans. Proc. South. Weed Sci. Soc., v. 35, p. 367, 1982.

BROW, H. M. Mode of action, crop selectivity, and soil relations of the sulfonylurea herbicides. Pestic. Sci., v. 29, p. $263-281,1990$.

CAMPBELL, J. R.; PENNER, D. Enhanced phytotoxicity of bentazon with organophosphate and carbamate insecticides. Weed Sci., v. 30, p. 324-326, 1982.

COSTA, J. A.; MARCHEZAN, T. Características dos estádios de desenvolvimento da soja. Campinas: Fundação Cargill, 1982. 30 p.

DIEHL, K. E.; STOLLER, E. W. Interaction of organophosfate insecticides with nicosulfuron and primisulfuron in corn. Proc. North Cent. Weed Sci., v. 45, p. 31-32, 1990.

EL-REFAI, A. R.; MOWAFY, M. Interaction of propanil with insecticides absorbed from soil and translocated into rice plants. Weed Sci., v. 21, p. 246-248, 1973.

FONNE-PFISTER, R. et al. Hydroxilation of primisulfuron inducible cytochrome $\mathrm{P}_{450}$ dependent monooxigenase system from maize. Pestic. Biochem. Physiol., v. 37, n. 1, p. 165$173,1990$.

Planta Daninha, Viçosa-MG, v. 23, n. 3, p. 527-534, 2005 
KAPUSTA, G.; KRAUSZ, R. F. Interaction of terbufos and nicosulfuron on corn (Zea mays). Weed Technol., v. 6, p. 999-1003, 1992.

KHOSRO, K.; SMITH JR. R. J.; TUGWELL, N. P. Interaction of propanil and selected insecticides on rice. Weed Sci., v. 34, p. 800-803, 1986.

KWON, C. S.; KELLS, J. J; PENNER, D. Combined effects of acetolactate synthase-inhibiting herbicides with terbufos and piperonyl butoxide on corn (Zea mays) and soybean (Glycine max). Weed Technol., v. 9, n. 4, p. 696-702, 1995.

LITHE, R. J. et al. Performance of terbufos on corn rootworm (Coleoptera: Chrysomelidae) in the Corn Belt. J. Econ. Entomol., v. 85, p. 1413-1424, 1992.

MORELAND, D. E.; CORBIN, F. T.; McFARLAND, J. E. Effects of safeners on the oxidation of multiple substrates by grain sorghum microsomes. Pestic. Biochem. Physiol., n. 45, p. 43-53, 1993.
PORPIGLIA, P. J. et al. A method to evaluate the differential response of corn (Zea mays) to sulfonylureas. Weed Sci. Soc. Am. Abstr., p. 61, 1990.

RAHMAN, A.; JAMES, T. K. Enhanced activity of nicosulfuron in combination with soil applied insecticides in corn (Zea mays). Weed Technol., v. 7, p. 824-829, 1993.

SILVA, A. A.; MELHORANÇA, A. L. Controle de plantas daninhas na cultura do milho. In:

Recomendações técnicas para a cultura do milho para o Mato Grosso do Sul. Dourados: EMBRAPA, 1991. p. 114-127. (Circular Técnica, 20)

SWANSON, C. R.; SWANSON, H. R. Inhibition of degradation of monuron in cotton tissue by carbamate insecticides. Weed Sci., v. 16, p. 481-484, 1968.

WALDROP, D. D.; BANKS, P. A. Interaction of herbicides with insecticides in soybeans (Glycine max). Weed Sci., v. 31, p. 730-734, 1983. 